Check for updates

Cite this: Mater. Adv., 2021, 2, 3981

Received 19th February 2021, Accepted 29th April 2021

DOI: 10.1039/d1ma00148e

rsc.li/materials-advances

\section{Near-infrared light enhanced starvation therapy to effectively promote cell apoptosis and inhibit migration $\dagger$}

\author{
Yan Huang, ${ }^{a}$ Peiwei Gong, (D)*ab Mingyue Liu, ${ }^{a}$ Jingyi Peng, ${ }^{a}$ Ruyue Zhang, ${ }^{a}$ \\ Changmin $\mathrm{Qi}^{a}{ }^{a}$ Yanqing Hou, ${ }^{a}$ Ming Liu, ${ }^{a}$ Dandan Wang ${ }^{* a}$ and Zhe Liu (D) *a
}

\begin{abstract}
Starvation therapy based on the catalytic property of glucose oxidase (GOx) holds great promise in cancer inhibition because of its non-drug use and negligible side effects. However, its inability to fundamentally kill tumor cells and low therapeutic efficiency heavily limit its further application. Herein, a nanoscale fluorinated graphene-based photothermal agent with high loading capacity of GOx was developed, and enhanced starvation/photothermal therapy (PTT) was achieved without using any chemo-drugs or additional reagents. Functionalization of polyethylene glycol and folic acid realized long-term stability and selectivity, and the highly conjugated structure allowed effective GOx adsorption by $\pi-\pi$ and hydrogen bond interactions. Fast consumption of glucose, toxic $\bullet \mathrm{OH}$ generated from hydrogen peroxide and hyperthermia from PTT synergistically guaranteed much better therapeutic efficiency. More importantly, this therapeutic model also effectively induced cell apoptosis with low GOx doses, and allowed us to demonstrate the first anti-migration example of starvation/PTT based on carbon materials. This work presents meaningful insights for cancer treatment without using any chemo-drugs and overcoming the imperfection of starvation therapy by using the carriers themselves instead of additional treatments.
\end{abstract}

\section{Introduction}

Due to its complexity and diversity, traditional treatments such as radiation therapy and chemotherapy etc. cannot sufficiently eradicate tumors, and the unescapable side effects not only damage human health, but also affect treatment effectiveness. ${ }^{1}$ The emerging starvation therapy based on cutting off nutrient sources to inhibit tumor cell growth without using any chemical drugs has been attracting great attention in recent years. $^{2}$ The growth and proliferation of tumors consume lots of energy and nutrients, and in view of the Warburg effect that cancer cells are more sensitive to changes in glucose concentration than normal cells, ${ }^{3}$ cutting off the glucose supply and starving cancer cells has been considered an effective strategy for cancer treatment. ${ }^{4}$ As a biocatalyst, glucose oxidase (GOx) effectively consumes glucose and oxygen in the tumor microenvironment, thereby providing an acidic and hypoxic environment. The reduction of glucose content effectively blocks the energy

\footnotetext{
${ }^{a}$ School of Chemistry and Chemical Engineering, Qufu Normal University, Qufu 273165, P. R. China. E-mail: gongpeiwei10@mails.ucas.ac.cn

${ }^{b}$ State Key Laboratory of Solidification Processing, Center of Advanced Lubrication and Seal Materials, Northwestern Polytechnical University, 517 Xi'an 710072, P. R. China

$\dagger$ Electronic supplementary information (ESI) available. See DOI: 10.1039/ d1ma00148e
}

supply of tumor cells. ${ }^{5,6}$ At the same time, the produced $\mathrm{H}_{2} \mathrm{O}_{2}$ during the decomposition process can be converted into ${ }^{\circ} \mathrm{OH}$ free radicals to kill cancer cells, which provides a non-invasive strategy. However, it is worth noticing that GOx needs oxygen for glucose catabolism, and the hypoxic environment in the tumor inhibits a rapid response. ${ }^{7,8}$ Meanwhile, the human body will continuously supply oxygen and nutrients to the cells. So a single starvation therapy cannot achieve full eradication of cancer cells, and long-term use of this monotherapy is also very prone to treatment resistance. ${ }^{9}$ Therefore, starvation therapy can only inhibit the growth rate of cancer cells, and cannot completely kill cancer cells. Due to these significant problems, it is imperative to combine other methods to improve the therapeutic effect. ${ }^{10}$

On the other hand, it is found that GOx can only execute the energy cutting-off function inside the cells, and thus accurate delivery of GOx into tumor cells plays an important role in starvation therapy. ${ }^{11}$ To address this problem, some promising approaches have been proposed. Zheng et al. reported enzymatic cascade nanoreactors to deliver Pd@Pt-GOx and hyaluronic acid and achieved starvation enhanced chemodynamic therapy (CDT). ${ }^{7}$ Han et al. established a co-ferrocene metal-organic framework and GOx as a cascade nanozyme for effective tumor therapy. ${ }^{12}$ Cui et al. also reported a sequential catalysis strategy for both tumor imaging and therapy, and to enhance the 
starvation therapy effect, a near-infrared fluorophore of IR780 was loaded to achieve photothermal therapy (PTT). ${ }^{13}$ Huang et al. developed GOx functionalized $\mathrm{SrCuSi}_{4} \mathrm{O}_{10}$ for starvation primed CDT, and PTT of deep-seated tumors was achieved. ${ }^{14}$ It is worth noticing that among the many combination methods, additional PTT reagents are needed and the synthesis procedure is often complex. ${ }^{15,34}$ Although great progress and many novel technologies have been achieved, few research studies have applied the good photothermal performance of the carrier itself to realize cooperative therapy of starvation therapy and PTT.

Fluorinated graphene (FG), as a new type of nano-medicine carrier, has unique advantages and has become a research hotspot in recent years. ${ }^{16-18}$ (1) High NIR absorption and photothermal properties. The highly conjugated carbon structure can effectively absorb $808 \mathrm{~nm}$ laser light and convert it into heat to achieve PTT with low doses. ${ }^{19-21}$ (2) New magnetic resonance imaging (MRI) contrasting agents and high lipophilicity. ${ }^{58,59}$ The introduction of fluorine atoms endows FG with high paramagnetism for MRI. And due to the high electronegativity of fluorine, $\mathrm{C}-\mathrm{F}$ bonds can induce biological responses to promote cell adhesion and proliferation. ${ }^{22,23}$ (3) High surface area and drug loading capacity. ${ }^{24,25}$ The aromatic structure and fluorine of FG allow it to form strong $\pi-\pi$ and hydrogen bond interactions with drugs, which makes it possible to absorb GOx and form a stable delivery system. ${ }^{26,27}$ (4) Tunable size and surface modification..$^{28-30}$ The size of FG can be well tuned to allow effective endocytosis, and the surface can be well modified to achieve good dispersity and selectivity toward cancer cells. All these novel properties guarantee that FG is a promising carrier for GOx delivery and synergistic treatment; ${ }^{31-33}$ however, to the best of our knowledge, there is no report that has achieved this goal and systematically studies its therapeutic effect.

Herein, we constructed a new FG-based GOx delivery system with specific recognition functions toward cancer cells to achieve good PTT enhanced starvation therapy. As demonstrated in Fig. 1, to build this system, FG was first oxidized and cut into much smaller sizes (namely, FGO) with oxygen groups, allowing good dispersibility and high NIR absorption. Then, folic acid (FA) was linked to FGO by amino-modified diamino-polyethylene glycol, which improved its biocompatibility and stability, and selectivity toward cancer cells was realized. ${ }^{35}$ GOx was easily adsorbed just by stirring the reactants together overnight, and cell experiments demonstrated that a very low dose of GOx could achieve good therapeutic effect, and NIR irradiation further greatly improved the therapeutic efficiency. Moreover, effective anti-migration properties were also achieved by this novel therapy model. It is considered that this work realizes the multi-modal synergistic treatment of PTT and starvation therapy, and provides a new idea for cancer treatment with high efficacy, negligible side effects and good anti-migration performance.

\section{Experimental details}

\subsection{Raw materials}

Chemical reagents for the synthesis and characterization of the nanocomposites are given in Part 1.1 of the ESI. $\dagger$

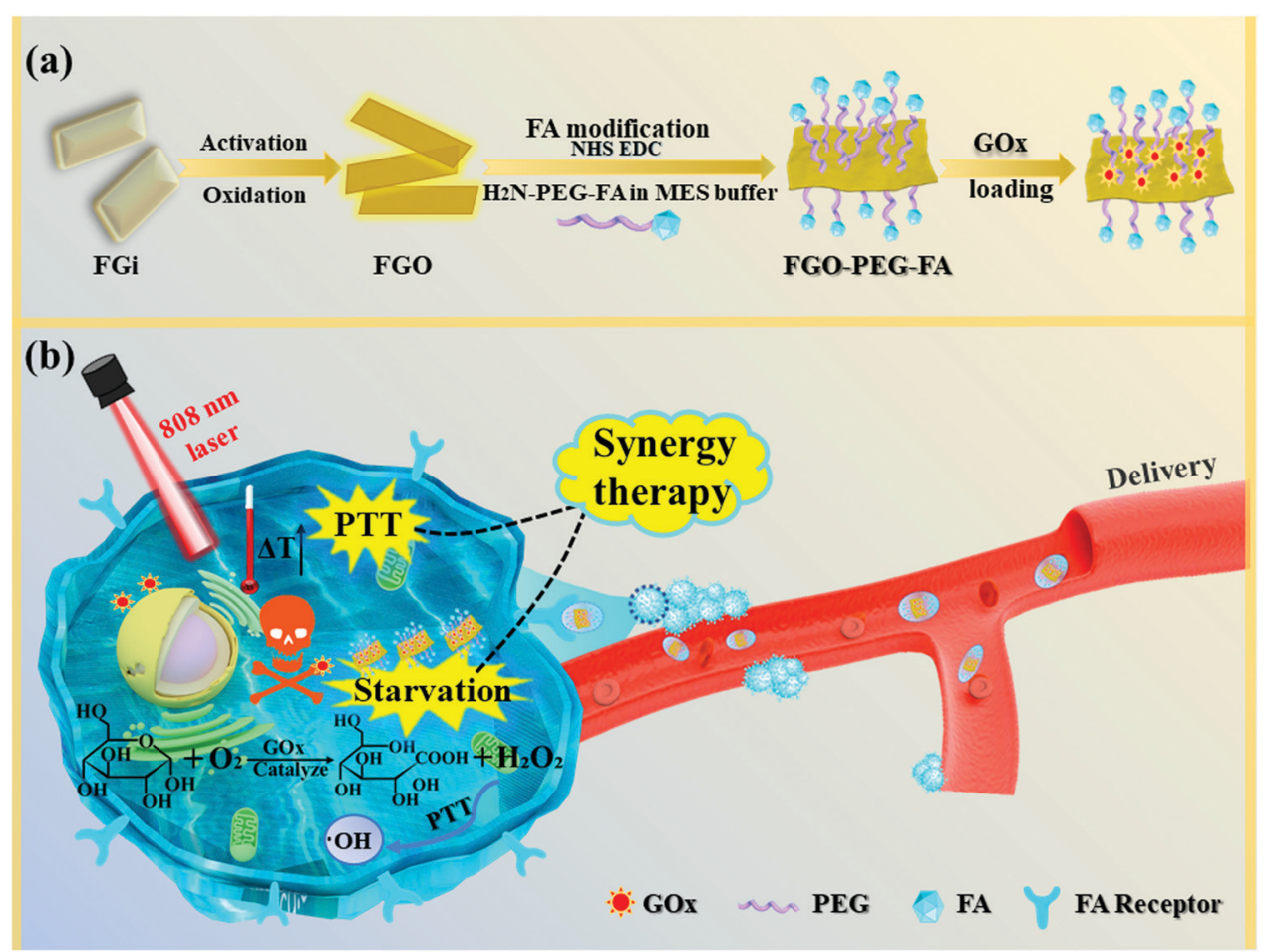

Fig. 1 Schematic illustration of (a) the synthesis processes for FGO-PEG-FA and (b) its facilitation of synergistic therapy in tumor treatment. 


\subsection{Activation of FGi and oxidation of Graphite fluoride (FGO)}

The active FG with some oxygen groups on the surface was prepared by sacrificing part of the $\mathrm{C}-\mathrm{F}$ bond based on our previous work with some modifications. ${ }^{60} 0.1 \mathrm{~g}$ of FG was put in a radius flask, and then ethylenediamine was added into the oil bath. The reaction was stirred for $3 \mathrm{~h}$ at $60{ }^{\circ} \mathrm{C}$ under nitrogen protection. After cooling to room temperature, $N$-methylpyrrolidine was added and sonicated at $200 \mathrm{~W}$ for $3 \mathrm{~h}$, and the supernatant of the solution after settling was poured out. Then the mixture was filtered through a $0.22 \mu \mathrm{m}$ microporous membrane and dried in an oven at $60{ }^{\circ} \mathrm{C}$.

In order to prepare nano-sized FGO and introduce more oxygen-containing groups, FG after activation was further oxidized, so as to facilitate the subsequent functional modification of related groups. Nanoscale FGO sheets were fabricated after the oxidation process. The specific experimental steps and related reactions are in Part 1.2 in the ESI. $\dagger$

\subsection{Preparation of $\mathrm{H}_{2} \mathrm{~N}$-PEG-FA and functionalized modification of FGO}

Diamino polyethylene glycol $\left(\mathrm{H}_{2} \mathrm{~N}-\mathrm{PEG}-\mathrm{NH}_{2}\right)$ was reacted with folic acid in a ratio of $1: 2$. The carboxyl group of folic acid was joined to the amino group at one end of polyethylene glycol by amidation at room temperature. ${ }^{55}$ The details of the experiment are in the Part 1.3 of the ESI. $\dagger$

After preparation of $\mathrm{H}_{2} \mathrm{~N}-\mathrm{PEG}-\mathrm{FA}$, modification of the carrier was carried out. Adding $5 \mathrm{mg}$ of FGO to $5 \mathrm{~mL}$ of water solution, the ultrasonic power was $300 \mathrm{~W}$ to promote dissolution. Then, $53.31 \mathrm{mg}$ of 2-morpholinoethanesulfonic acid (MES) was added as a buffer, followed by $95.85 \mathrm{mg}$ of 1-(3-dimethylaminopropyl)3-ethyl ammonia diimide hydrochloride (EDC $\mathrm{HCl}$ ) and $57.55 \mathrm{mg}$ of $\mathrm{N}$-hydroxysuccinimide (NHS). Ultrasound was performed for 1 hour at a power of $300 \mathrm{~W}$ to completely disperse the mixture. Then the mixture was stirred at room temperature for $12 \mathrm{~h}$ at a speed of $30 \mathrm{rad} \mathrm{s}^{-1}$. After adding $100 \mu \mathrm{L}$ of $N, N$ diethylethylamine to the reaction solution to adjust the $\mathrm{pH}$ of the reaction solution to about $9,0.05 \mathrm{mmol} \mathrm{H}_{2} \mathrm{~N}-\mathrm{PEG}-\mathrm{FA}$ was added and stirred at room temperature for 4 days at a speed of $30 \mathrm{rad} \mathrm{s}^{-1}$. After obtaining the product solution, it was subjected to dialysis (3000 Da) for several days, during which the water was changed every 5 hours. Then FGO-PEG-FA was obtained by vacuum freeze-drying.

\subsection{In vitro loading of GOx}

$60 \mathrm{mg}$ of FGO-PEG-FA was dissolved and sonicated at $200 \mathrm{~W}$ for $5 \mathrm{~min} .120 \mathrm{mg}$ of GOx was then added into the solution and sonicated again for $5 \mathrm{~min}$ to dissolve the sample. The mixed solution was stirred on a magnetic stirrer at $15 \mathrm{rad} \mathrm{s}^{-1}$ for $24 \mathrm{~h}$ at room temperature. Then the solution was centrifuged to remove free GOx from the upper liquid layer at $9000 \mathrm{rpm}$ for $5 \mathrm{~min}$. The collected solid products were washed alternately with ethanol and distilled water three times. Finally, FGO-PEG-FA + GOx was obtained by vacuum freezedrying. The loading of GOx on FGO-PEG-FA was determined by infrared spectroscopy (FTIR), thermogravimetric analysis (TGA) and so on.

\subsection{Cell experiment}

2.5.1 Intracellular fluorescence imaging. To facilitate the observation of intracellular drug uptake and changes in fluorescence intensity, FGO-PEG-FA + Rhodamine B was added to the culture medium of HeLa cells and A549 cells incubated for different times. Please refer to Part 1.5 of the $\mathrm{ESI} \dagger$ for more details of the experiment.

2.5.2 Intracellular drug uptake and specific recognition. Flow cytometry was performed as a pattern to study the targeted recognition behavior of HeLa cells. Experimental details for the samples and procedure can be found in Section 1.6 of the ESI. $\dagger$

2.5.3 In vitro synergistic therapy. The cytotoxicity of FGO-PEG-FA was evaluated through MTT assay technology. Meanwhile, cancer cells were incubated at different concentrations of samples and subjected to $808 \mathrm{~nm}$ near-infrared light irradiation to compare the effects of monotherapy and cooperative therapy. Please refer to Part 1.7 of the ESI $\dagger$ for specific sample treatment and operation methods.

2.5.4 Cell migration assay. A wound-healing assay was used to assess the anti-migration ability of HeLa cells after special treatment. In a nutshell, an inverted microscope was used to evaluate the migration of HeLa cells after carrier, GOx loading and near-infrared light irradiation treatment. The concrete experimental details are provided in Part 1.8 of the ESI. $\dagger$

2.5.5 Apoptosis assay. Briefly, after staining HeLa cells with Annexin V-FITC/PI, apoptosis was quantified by flow cytometry analysis. The specific sample doses used and photothermal treatment parameters can be found in Part 1.9 of the ESI. $\dagger$

\subsection{Performance and characterization}

Information on the experimental methods and instruments used in the various tests in this study to analyze the chemical composition, photothermal properties (refer to Part 1.4 of the $\mathrm{ESI} \dagger$ for specific details of the PTT experiments), target recognition functions, drug loading, and cellular interactions, etc. of the substances, are provided in Part 1.10 of the ESI. $\dagger$

\section{Results and discussions}

For the sake of preparing few-layer sheets, thin and transparent FG at a micron level could be obtained through activation treatment and sonic exfoliation processes (Fig. S1, ESI $\dagger$ ). First, because of the characteristics of surface hydrophobic graphene, ${ }^{56}$ fluorinated graphite was used to carry out appropriate oxidation reactions, which improved the hydrophilicity and the reaction activity. ${ }^{36}$ After being further oxidized and separated, FG was converted into FGO, and the size became smaller, which greatly improved the solubility and could be used for subsequent target modification. Then, when PEG was connected to the targeting molecule folic acid (FA), and encapsulated in FGO, nanoscale FGO-PEG-FA could be obtained.

\subsection{Structure characterization}

TEM observation (Fig. 2a) showed that, compared to FG with a large size (Fig. S1, ESI $\dagger$ ), FGO-PEG-FA possessed an average size of about $50 \mathrm{~nm}$ (Fig. S2, ESI $\dagger$ ). In addition, dynamic light 

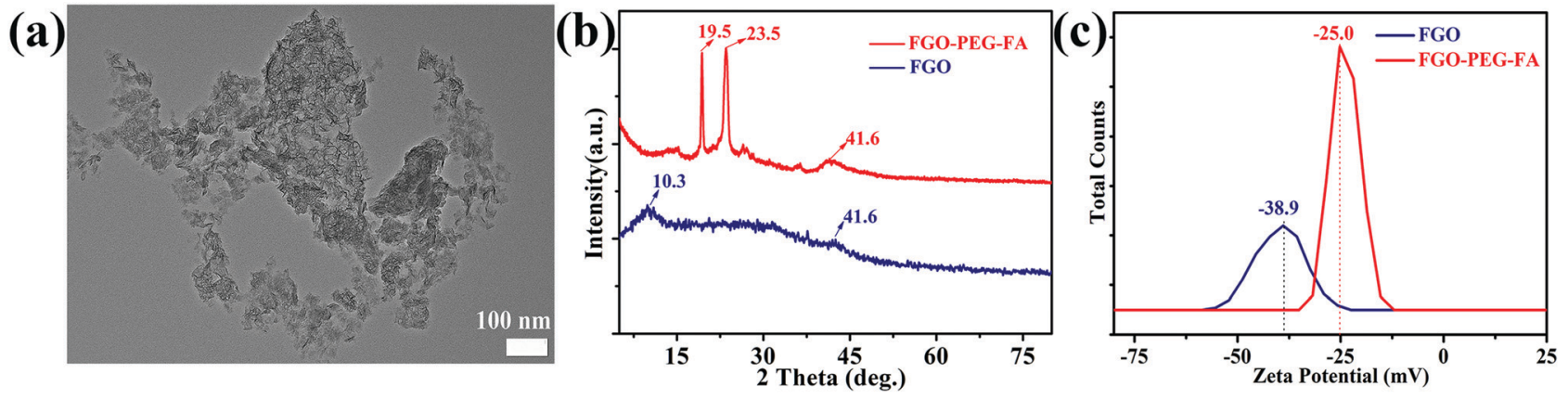

Fig. 2 (a) TEM image of FGO-PEG-FA. (b) XRD patterns and (c) zeta potential images for FGO and FGO-PEG-FA.

scattering (DLS) analysis showed that the size of FGO-PEG-FA was about $70-100 \mathrm{~nm}$, a little larger than that from TEM data (Fig. S3, ESI $\dagger$ ). This was mostly because, after PEG-FA modification, the long chains of PEG made the hydration degree become stronger and thus the DLS size was larger, similar to previous work. ${ }^{53,54}$ Such a small size considerably enhanced the cell uptake by endocytosis. ${ }^{37} \mathrm{X}$-ray diffraction data (XRD, Fig. 2b) showed that FGO exhibited typical peaks at $2 \theta=10.3^{\circ}$ and $41.6^{\circ}$; the former corresponded to the (001) pattern that reflected carbon materials with high fluorine contents, and the latter was ascribed to (100) pattern in a classical graphene-like structure. ${ }^{38}$ For FGO-PEG-FA, new typical peaks located at $19.5^{\circ}$ and $23.5^{\circ}$ were detected, which were representative peaks of $\mathrm{H}_{2} \mathrm{~N}-\mathrm{PEG}-\mathrm{NH}_{2}{ }^{39}$ This revealed that the original carbon structure arrangement was maintained and the surface was well modified by $\mathrm{H}_{2} \mathrm{~N}-\mathrm{PEG}-\mathrm{NH}_{2}$. Zeta potential measurements (Fig. 2c) indicated that apparent zeta potential of $\mathrm{FGO}$ was about $-38.9 \mathrm{mV}$, while the value of FGO-PEG-FA was about $-25.0 \mathrm{mV}$. It was reported that the surface of FGO had a static negative charge due to oxygen groups, and the increased potential of FGO-PEG-FA was mostly due to the fact that the diamino-polyethylene glycol had a relatively large positive charge ${ }^{40}$ and thus raised the potential, which further proved the successful modification process.

\subsection{Chemical composition}

The chemical composition analyses revealed that characteristic peaks in FGO were also detected in FGO-PEG-FA, such as C-F stretching vibration at $1211 \mathrm{~cm}^{-1},-\mathrm{OH}$ stretching vibration at $1350 \mathrm{~cm}^{-1}$ and $-\mathrm{COOH}$ at $1730 \mathrm{~cm}^{-1}$ (Fig. 3a). ${ }^{41}$ After functional modification, the absorption peak of the $\mathrm{C}-\mathrm{O}-\mathrm{C}$ anti-symmetric stretching vibration of polyethylene glycols at $1107 \mathrm{~cm}^{-1}$ was also detected in the FTIR data of FGO-PEG-FA. ${ }^{42} \mathrm{~A}$ strong peak also appeared at $2863 \mathrm{~cm}^{-1}$, resulting from $\mathrm{C}-\mathrm{H}$ stretching vibrations in methylene. Furthermore, the characteristic peak for $\mathrm{NH}-\mathrm{CO}\left(1636 \mathrm{~cm}^{-1}\right)$ formed by the bonding of FGO and PEG-FA, and PEG and FA through amidation reaction was also found in the product. ${ }^{43}$ All of these results confirmed the successful synthesis of FGO-PEG-FA, which was also proved in the XPS element analysis (Fig. 3b). Detailed XPS survey spectrum of FGO-PEG-FA showed that the elements of carbon $(285.5 \mathrm{eV})$, oxygen $(532.2 \mathrm{eV})$, and fluorine $(688.7 \mathrm{eV})$ were detected. ${ }^{44}$ Additionally, nitrogen (400.2 eV) from PEG- $\mathrm{NH}_{2}$ and FA was also found. ${ }^{38}$ The $\mathrm{N} 1{ }^{62}$ and $\mathrm{F} 1$ spectra further proved effective surface functionalization and preservation of the $\mathrm{C}-\mathrm{F}$ bonds.

\subsection{Photothermal performance}

Due to the well confined structure and smaller size, it is speculated that FGO-PEG-FA should possess excellent photothermal conversion properties. ${ }^{45}$ As shown in Fig. 4, in this experiment, we evaluated the photothermal conversion capacity of the material by monitoring the temperature rise of FGO aqueous solution under the irradiation of $808 \mathrm{~nm}$ near-infrared light. It was obvious that the temperature of the solution rose with the increase of FGO-PEG-FA concentration (Fig. 4a). Meanwhile, the increase of power density (Fig. $4 \mathrm{~b}$ ) also presented a positive effect on the temperature rise. Even at a very low concentration of $0.4 \mathrm{mg} \mathrm{mL} \mathrm{m}^{-1}$ and a low power density of $0.9 \mathrm{~W} \mathrm{~cm}^{-2}$, the temperature of the FGO-PEG-FA suspension instantly increased up to $43^{\circ} \mathrm{C}$. Such a temperature was proved to greatly enhance the efficacy of drug toxicity towards cancer cells. ${ }^{46}$ Moreover, FGO-PEG-FA exhibited excellent stability even after six on/off irradiation cycles (Fig. 4c). The stability and rapid temperature rise characteristics were considered to lay a solid foundation for its practical applications.

\subsection{Drug loading performance}

GOx has a favorable selective catalysis, which oxidizes glucose with $\mathrm{O}_{2}$ into glucose acid and $\mathrm{H}_{2} \mathrm{O}_{2}$ frequently and effectively. ${ }^{5,6}$ The consumption of glucose and oxygen heavily affects the energy supply and intratumoral oxygen levels, and finally results into effective cancer cell inhibition. Meanwhile, the produced $\mathrm{H}_{2} \mathrm{O}_{2}$ with high concentrations can result in cancer cell death. ${ }^{47}$ Therefore, effective delivery of GOx into cells can obtain good starvation therapy of cancer cells. The strong $\pi-\pi$ interactions and hydrogen interactions between FGO-PEG-FA and GOx make it possible to load GOx in a facile manner. The mild loading process of the enzyme in this strategy allowed the drug delivery system to inherit the excellent chemical and structural properties of FGO-PEG-FA (Fig. S5, ESI $\dagger$ ). After being stirred for $24 \mathrm{~h}$ and further purified by centrifugation and dialysis, the obtained products were analyzed and related results were shown in Fig. 5. The peak near $1650 \mathrm{~cm}^{-1}$ belonged to $\mathrm{C}=\mathrm{O}$ stretching vibration of $\mathrm{GOx},{ }^{48}$ and this characteristic peak was present in FGO-PEG-FA + GOx, confirming the effective loading process. This situation is also 
(a)
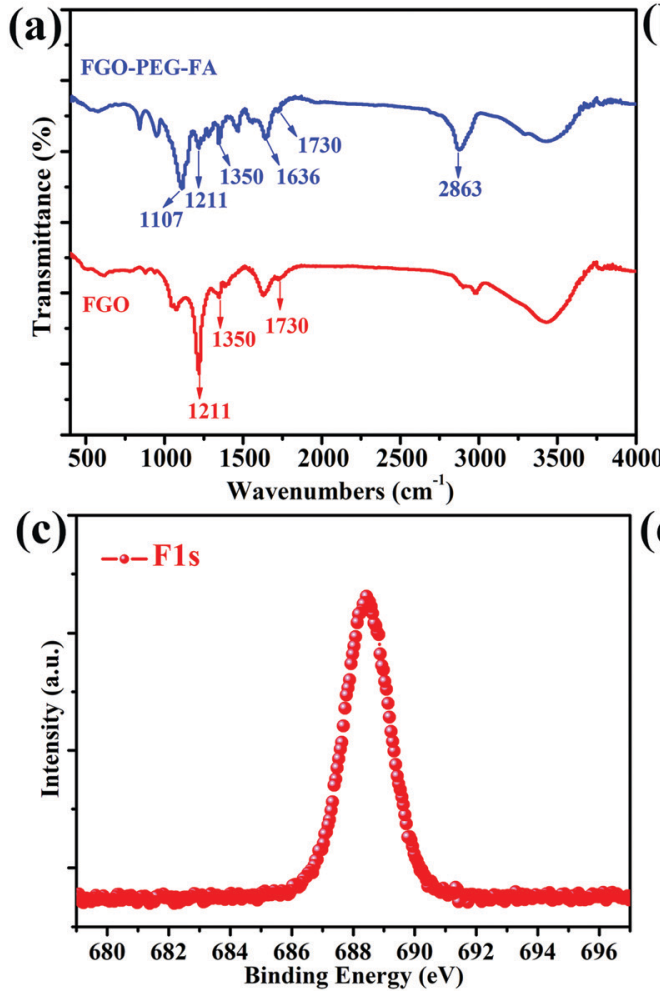

(b)

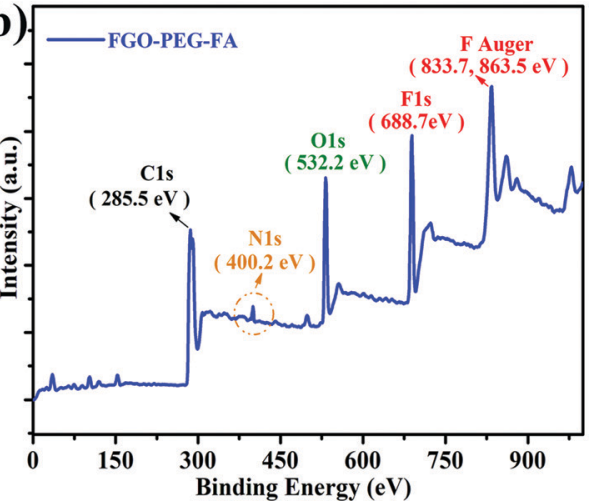

Fig. 3 (a) FTIR data for FGO and FGO-PEG-FA. (b) XPS survey, (c) N1s and (d) F1s spectrum of FGO-PEG-FA.
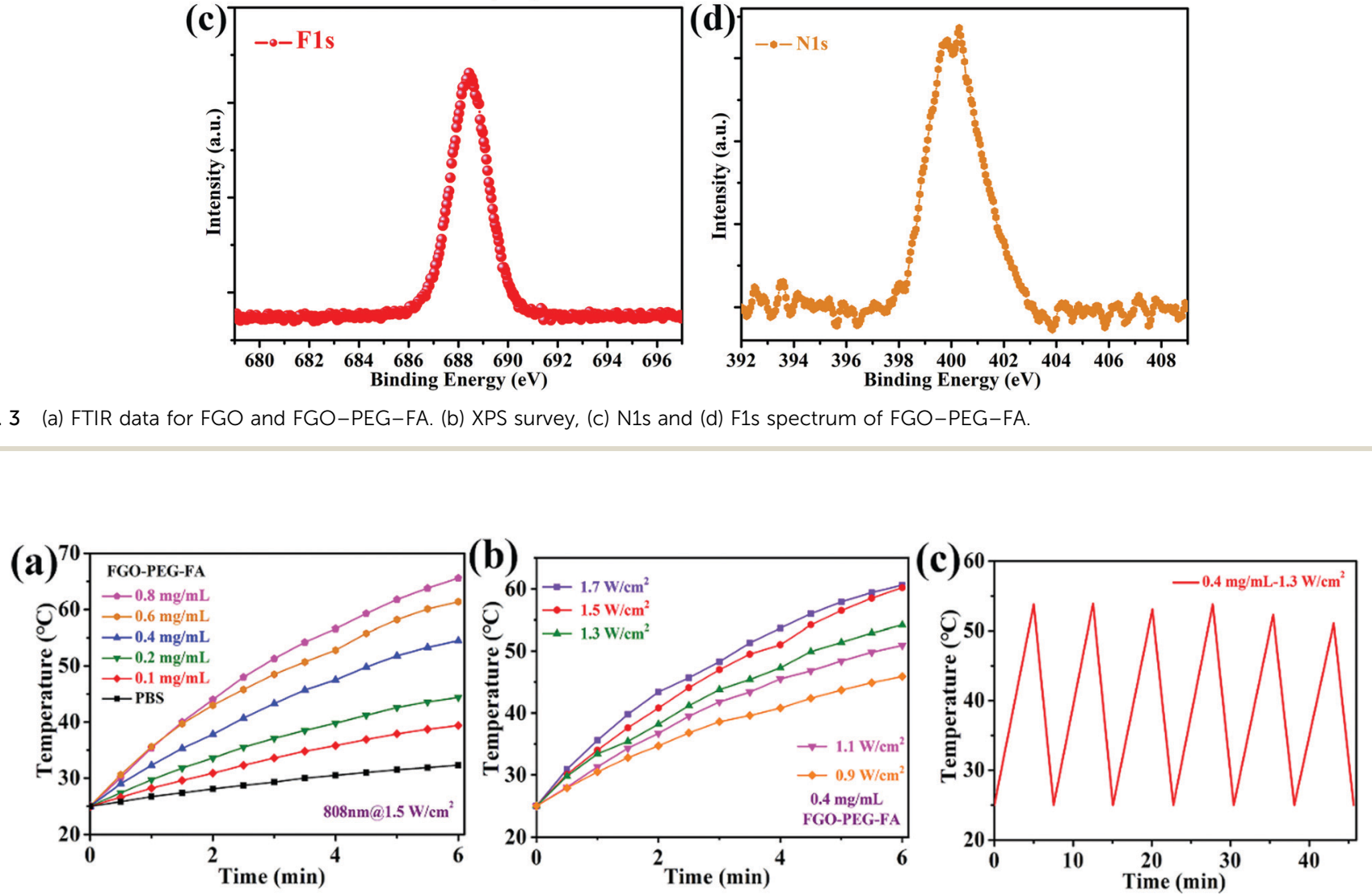

Fig. 4 Photothermal performance study. Analysis of the temperature after exposure to NIR irradiation ( $808 \mathrm{~nm}, 1.5 \mathrm{~W} \mathrm{~cm}{ }^{-2}$ ) as a function of (a) concentration and (b) power density. (c) Cycle stability results.

confirmed by TGA data in Fig. $5 \mathrm{~b}$. It can be observed that the FGO profile exhibited a slight weight loss below $120{ }^{\circ} \mathrm{C}$, induced by the removal of water molecules. Subsequently, most of the weight loss appeared between 160 and $230{ }^{\circ} \mathrm{C}$, which was attributed to the release of $\mathrm{CO}$ and $\mathrm{CO}_{2}$ from some unstable functional groups on the surface. In addition, the rate of weight loss slowed down thereafter until the temperature rose to $600{ }^{\circ} \mathrm{C} .{ }^{49}$ Compared to pure FGO, FGO-PEG-FA + GOx with targeted modification and drug loading showed a larger weight loss between 200 and $450{ }^{\circ} \mathrm{C}$, mainly due to the decomposition of PEG-FA fragments. About $11 \%$ weight loss was observed in the range of $416-550{ }^{\circ} \mathrm{C}$, attributed to the decomposition of organic molecules in $\mathrm{H}_{2} \mathrm{~N}-\mathrm{PEG}-\mathrm{NH}_{2},{ }^{50}$ and there was practically no more weight loss beyond this temperature range. When heated to $800{ }^{\circ} \mathrm{C}$, mass losses of $94.83 \%$ and $99.06 \%$ were identified for FGO-PEG-FA and FGO-PEG-FA + GOx, respectively. The GOx loading ratio to FGO-PEG-FA was calculated to be $4.24 \%$.

GOx can be adsorbed on the surface of FGO-PEG-FA, resulting in the turn-off fluorescence of GOx due to the fluorescence resonance energy transfer effect. ${ }^{23}$ This mechanism was further used to characterize the loading amount of GOx. As shown in Fig. 6a, the fluorescence peak shapes of the series of solutions were basically the same, while the characteristic emission peak of GOx at $350 \mathrm{~nm}$ gradually weakened with the increase of the FGO-PEG-FA concentration. When the concentration reached 
(a)

(a)

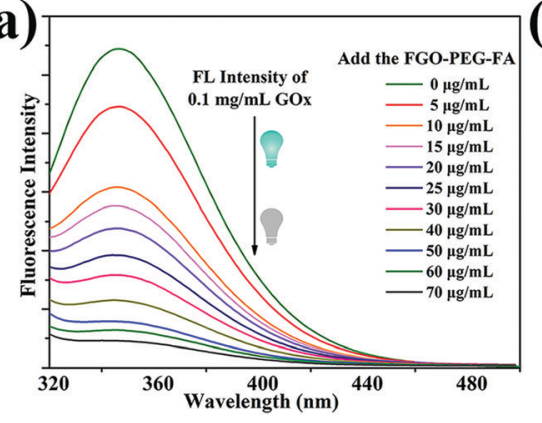

(b)

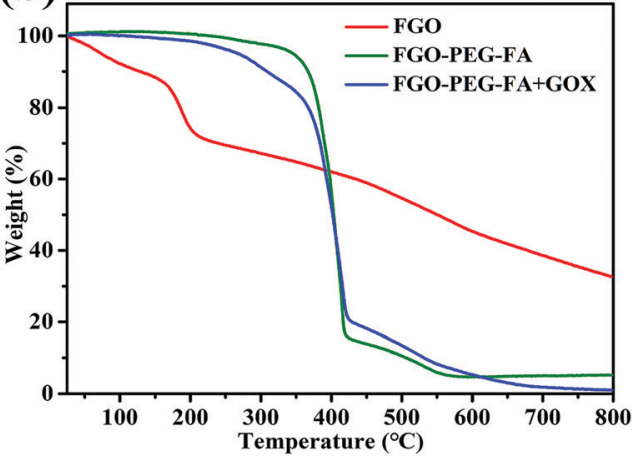

Fig. 5 (a) FTIR data for FGO-PEG-FA + GOx and GOx. (b) TGA curves of FGO, FGO-PEG-FA, and FGO-PEG-FA + GOx under an argon atmosphere.

Fig. 6 (a) Fluorescence intensity of GOx solutions at a concentration ratio of $0.1 \mathrm{mg} \mathrm{mL}^{-1}$ in the presence of various concentrations of FGO-PEG-FA. (b) Solution stability of FGO-PEG-FA and FGO-PEG-FA + GOx in PBS solution and Dulbecco's modified Eagle's medium (DMEM).

$70 \mu \mathrm{g} \mathrm{mL} \mathrm{m}^{-1}$, it was found that the GOx fluorescence was almost quenched, indicating that nearly all of the GOx was absorbed. The changes of the fluorescence spectra not only confirmed that FGO successfully absorbed GOx, but also allowed us to calculate the loading capacity to be $0.81 \mathrm{mg} \mathrm{mg}^{-1}$, agreeing well with the TGA results. Furthermore, in view of ensuring that the drug delivery system can achieve practical therapeutic applications, the maintenance of a stable and dispersed state in a slightly acidic tumor living environment or a normal living environment is an important factor. Just as displayed in Fig. 6b, both FGOPEG-FA and FGO-PEG-FA + GOx showed good dispersibility in PBS solution or DMEM solution. They all showed a transparent state, and could be uniformly dispersed in these media, and this conclusion was also proved by the stability test in a UV-Vis spectrophotometer (Fig. S4 and S5b, ESI $\dagger$ ), holding great promise for drug delivery and other biological applications.

\subsection{Study of cellular uptake and specific recognition of tumor cells}

To confirm the cellular uptake and selectivity toward cancer cells with FA receptors, HeLa cells (FA-positive) and A549 cells (FA-negative) were incubated with FGO-PEG-FA + RhB under the same conditions. After treating the cells with FGO-PEG-FA + $\mathrm{RhB}$ for $1 \mathrm{~h}$, the red fluorescence of RhB mainly appeared in the cytoplasm of HeLa cells (Fig. S6a, ESI $\dagger$ ), while the fluorescence was barely visible in A549 cells (Fig. S6b, ESI $\dagger$ ), indicating effective and selective endocytosis of the nanocarrier. Moreover, with the extension of time, the fluorescence intensity increased significantly after four hours, and this revealed that more FGO-PEG-FA was being taken into HeLa cells and more Rhodamine B was released (Fig. 7a). And the fluorescence intensity of A549 cells (FA-negative) (Fig. 7b) was much weaker than that of HeLa cells. Thus, the difference in fluorescence intensity between the two types of cells shows that FGO-PEG-FA can specifically identify tumor cells that overexpress FA

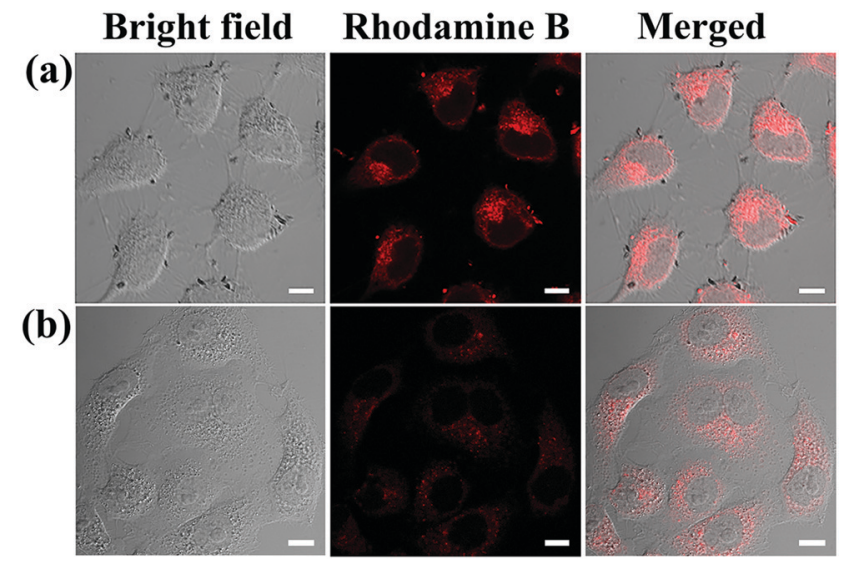

Fig. 7 LCSM images of (a) HeLa cells and (b) A549 cells treated with FGOPEG-FA + Rhodamine B for $4 \mathrm{~h}$ ([FGO-PEG-FA]: $20 \mu \mathrm{g} \mathrm{mL}^{-1}$, [Rhodamine B]: $0.1 \mathrm{mM})$, scale bar $=10 \mu \mathrm{m}$. 

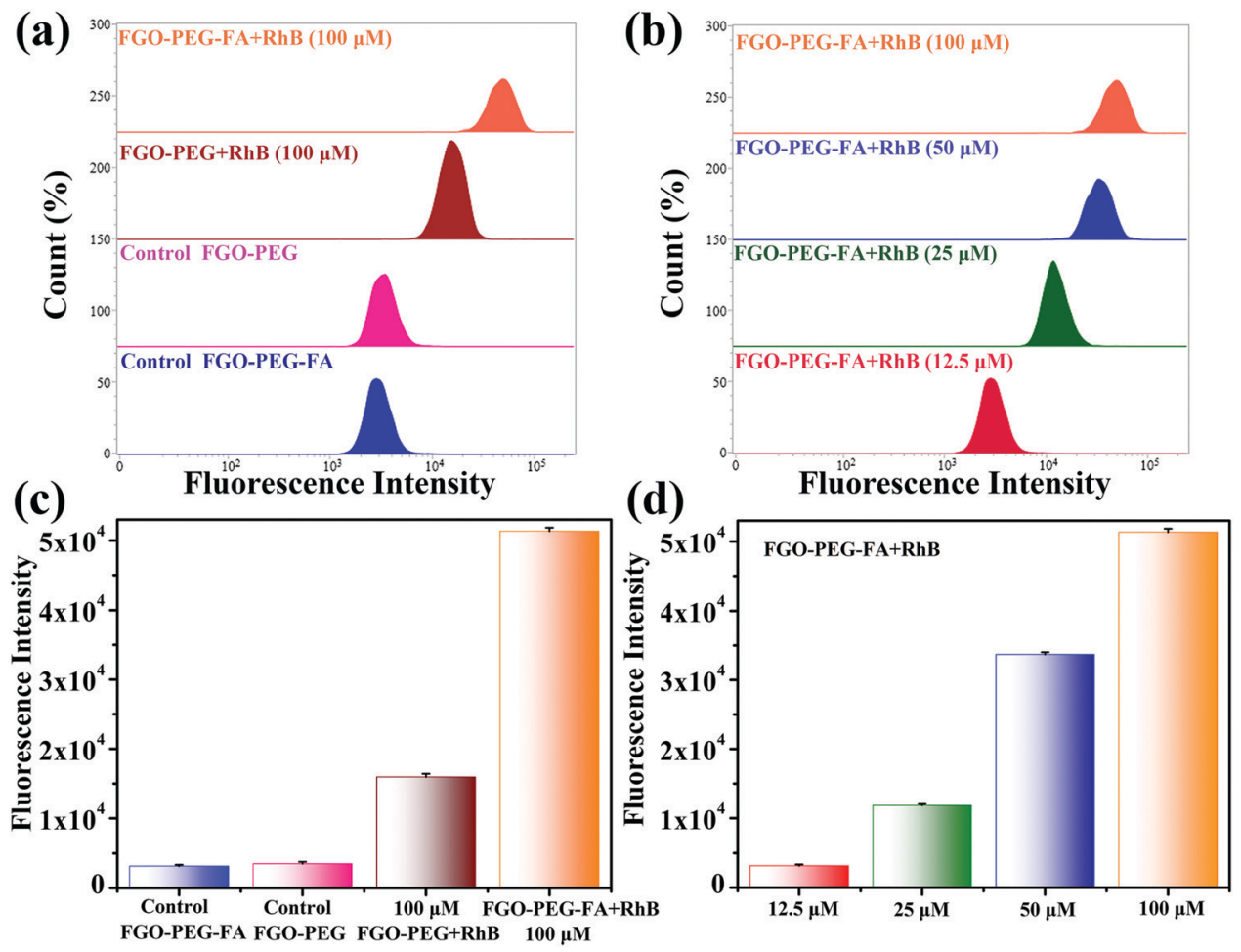

Fig. 8 Flow cytometry data of the HeLa cells incubated with (a) FGO-PEG + RhB and FGO-PEG-FA + RhB and (b) different concentrations of FGO-PEG-FA + RhB under the same conditions. (c) and (d) show the corresponding average results obtained by several experiments under the same conditions.

receptors. ${ }^{57}$ The above data not only indicated that FGO-PEG-FA was readily endocytosed into cells, but also proved that the targeted modification enabled FGO-PEG-FA to have a specific recognition function, which provided the feasibility for drug release and regulation.

In order to have a more thorough comprehension of the uptake behavior of cells and further verify the targeting capability, flow cytometry experiments were conducted. HeLa cells with FApositive receptors were incubated with FGO-PEG $+\mathrm{RhB}$ and different concentrations of FGO-PEG-FA + RhB and the corresponding results were provided in Fig. 8. It was found that much higher fluorescence intensity was detected from the cells treated by FGO-PEG-FA + RhB than FGO-PEG + RhB, which indicated that FGO-PEG-FA could specifically recognize HeLa cells and resulted in more endocytosis and release. This result was also in good agreement with the LCSM test data. Moreover, Fig. 8 showed that this specific recognition would become more obvious as the concentration of FGO-PEG-FA + RhB increased. Several parallel experiments under the same conditions achieved similar results and the related data were provided in Fig. 8(c and d).

\subsection{In vitro synergistic therapeutic efficacy}

Based on the excellent performance, we launched research work to study the therapeutic effects on cancer cells. First of all, in order to ensure the possibility of biomedical applications of FGO-PEG-FA, the study of its toxicity is crucial. As shown in Fig. 9a,
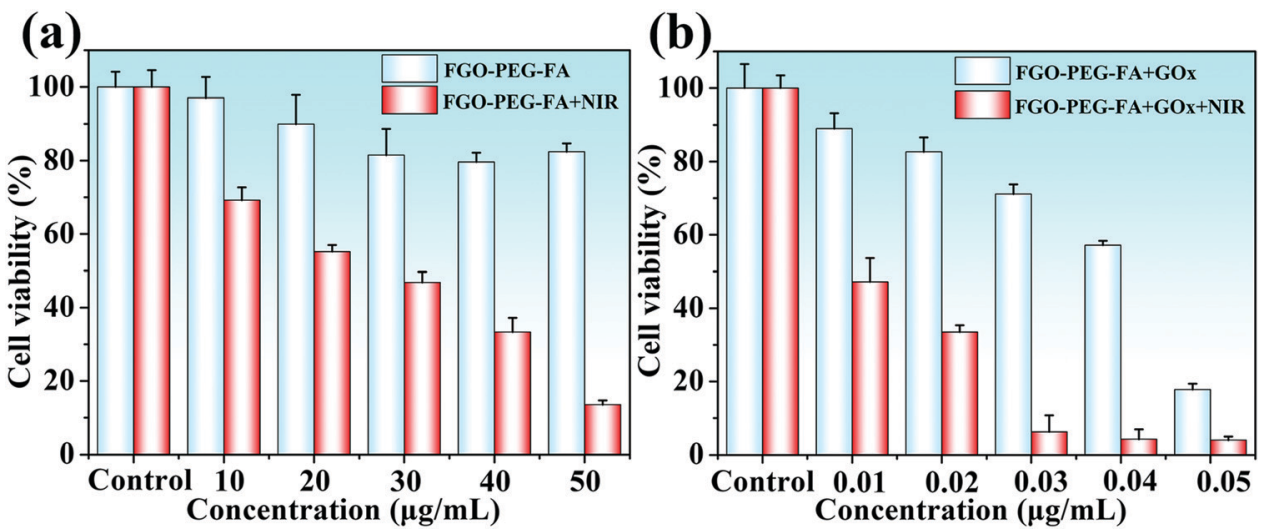

Fig. 9 (a) Toxicity of FGO-PEG-FA and PTT toward HeLa cells. (b) Synergistic therapeutic effect on HeLa cells. 

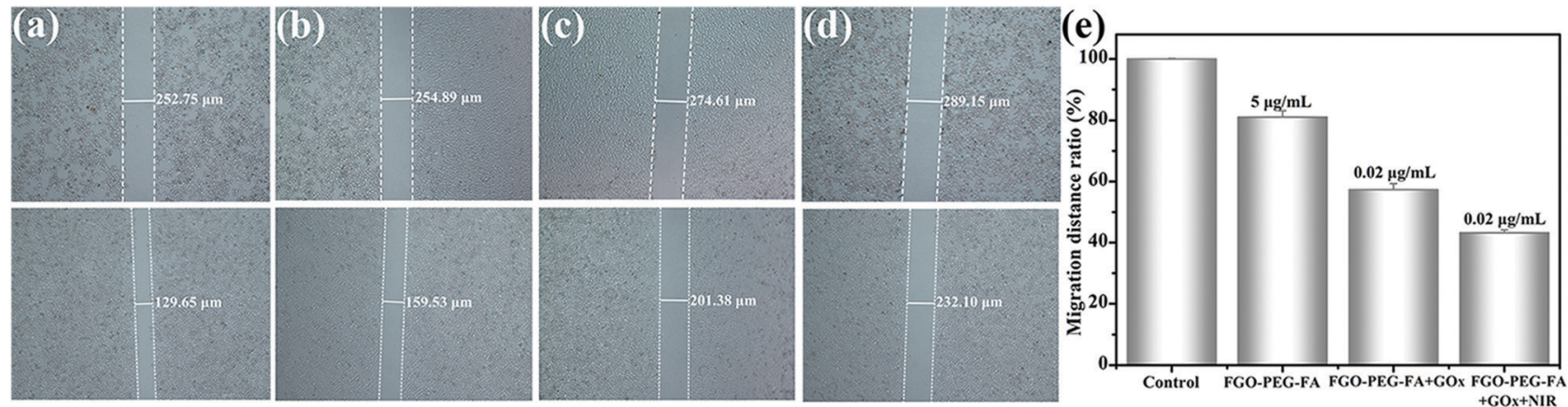

Fig. 10 Typical microscope images of cell migration. HeLa cells cultured in DMEM (a) without any treatment, (b) with $10 \mu \mathrm{g} \mathrm{mL}{ }^{-1} \mathrm{FGO}-\mathrm{PEG}-\mathrm{FA}$ and (c) with FGO-PEG-FA loaded with $0.02 \mu \mathrm{g} \mathrm{mL} \mathrm{m}^{-1} \mathrm{GOx}$. (d) The same concentrations of FGO-PEG-FA + GOx as above and NIR for 5 minutes. (e) Statistical average results of HeLa cells migration distance ratio under the same experimental conditions.

after treating HeLa cells with FGO-PEG-FA for 24 hours, the cell survival rate decreased slightly and indicated low toxicity of the products. At the same time, the survival rate of HeLa cells irradiated with $808 \mathrm{~nm}$ near-infrared light decreased significantly, and showed a dose-dependent down-regulation, indicating the excellent photothermal response of FGO-PEG-FA. To combine the superior performance of starvation therapy and PTT to achieve a more efficient treatment effect, a low concentration of GOx was loaded onto FGO-PEG-FA and incubated with HeLa cells. The study found that as the concentration of GOx increased, the inhibitory effect on the growth of cancer cells was enhanced. When the drug concentration reached $0.05 \mu \mathrm{g} \mathrm{mL}^{-1}$, the cell survival rate was only about $20 \%$. And this effect was more effective after PTT treatment. As shown in Fig. 9b, when using synergistic treatment, only at a low drug concentration of $0.03 \mu \mathrm{g} \mathrm{mL}{ }^{-1}$, the cancer cell growth inhibition ratio reached $90 \%$. As a photothermal conversion material, FGO-PEG-FA could accumulate heat in the tumor to accelerate the death of tumor cells. Meanwhile, hyperthermia induced by PTT could also accelerate the uptake of nanocarriers and promote drug release. ${ }^{51}$ The above studies not only showed the high biosafety and biocompatibility of FGO-PEG-FA, but

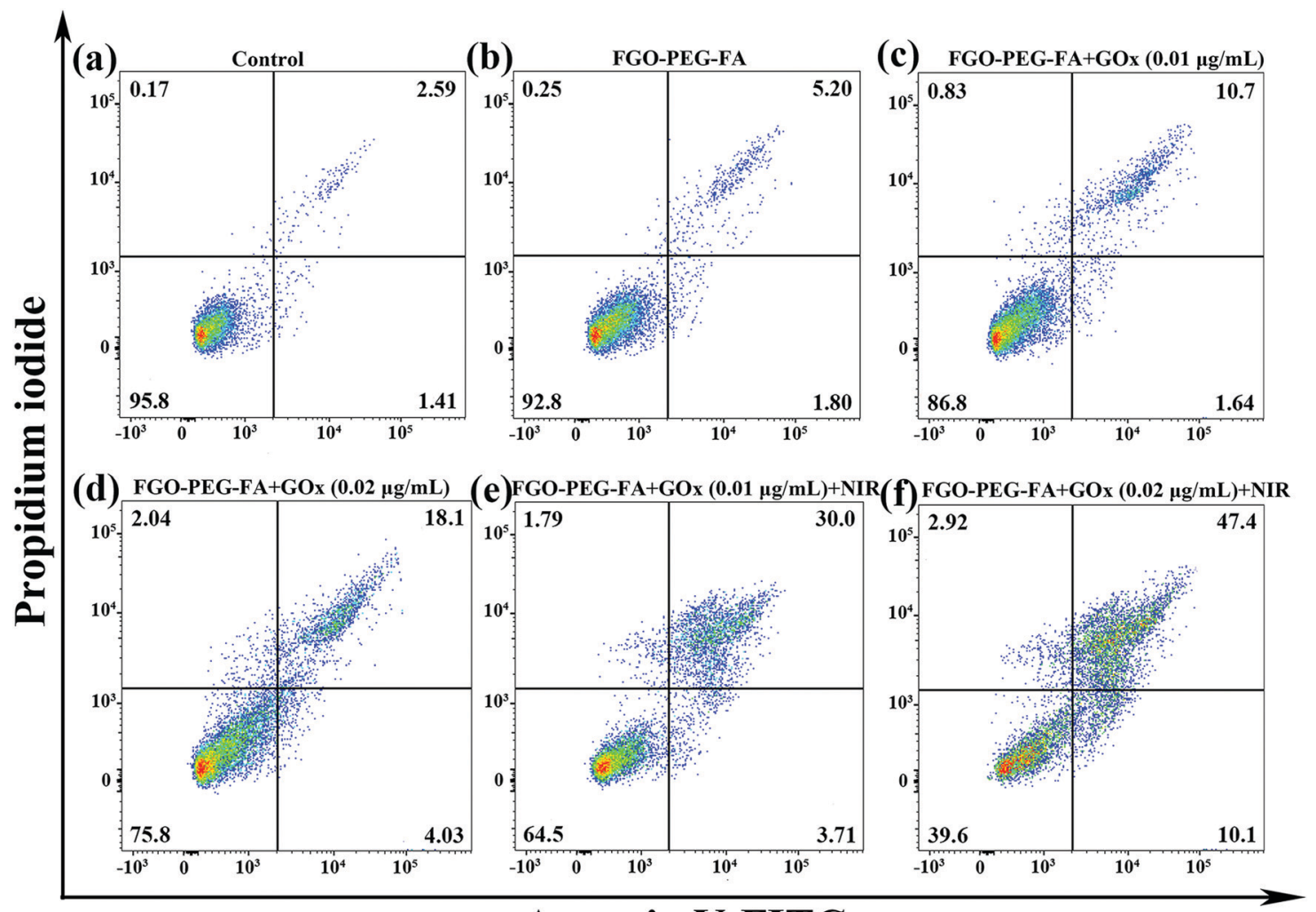

Annexin V-FITC

Fig. 11 Apoptosis evoked by (a) control, (b) $10 \mu \mathrm{g} \mathrm{mL}^{-1} \mathrm{FGO}-\mathrm{PEG}-\mathrm{FA}$, and FGO-PEG-FA loaded with different concentrations of GOx: (c) $0.01 \mu \mathrm{g} \mathrm{mL}^{-1}$ and (d) $0.02 \mu \mathrm{g} \mathrm{mL}^{-1}$. (e) FGO-PEG-FA + GOx $\left(0.01 \mu \mathrm{g} \mathrm{mL}{ }^{-1}\right)+\mathrm{NIR}$ and (f) FGO-PEG-FA + GOx $\left(0.02 \mu \mathrm{g} \mathrm{mL}{ }^{-1}\right)+\mathrm{NIR}$ for $24 \mathrm{~h}$. 
also proved outstanding tumor cell suppression brought by the combination of starvation therapy and PTT, providing new ideas for cancer treatment.

\subsection{Study on the inhibition of cell migration}

The most pervasive activity following tumor progression was tumor metastasis, which induced lesions in other tissues and organs and often became a fatal hazard for patients. ${ }^{52,61}$ Therefore, effective resistance of migration was crucial for tumor treatment. The anti-migration effect on HeLa cell metastasis was evaluated by the widely used scratch assay. As shown in Fig. 10, after $24 \mathrm{~h}$ of warm incubation, untreated HeLa cells exhibited an exuberant growth posture, demonstrating the strong metastatic properties of the tumor cells. The situation wasn't changed when HeLa cells were incubated with FGO-PEG-FA alone. On the contrary, cell migration was greatly inhibited by treatment with FGO-PEGFA + GOx, and the migration ratio was $67.70 \%$. When irradiated with additional NIR light, the cell motility was further significantly inhibited under the same GOx concentration incubation, with a migration distance ratio of only $43.20 \%$ compared to the control group. These results also demonstrated that the combination of PTT and starvation therapy could achieve considerable anti-migration effects and reduce the risk of tumor metastasis.

\subsection{In vitro apoptosis study}

Encouraged by the above research, we used flow cytometry to explore the apoptosis behavior. Among them, the Annexin-V-FITC/P detection method was used for cell staining. As illustrated in Fig. 11, compared with the control group, HeLa cells almost did not undergo apoptosis on incubation with the pure carrier, indicating that FGO-PEG-FA was safe and had negligible toxic side effects. As for FGO-PEG-FA + GOx, the apoptotic ratio showed a dosedependent increase of $12.34 \%$ and $22.13 \%$, respectively. This result proved the toxic effect of GOx on tumor cells, which could consume $\mathrm{O}_{2}$, decompose glucose, and achieve good starvation therapy.

Meanwhile, it is worth noting that FGO-PEG-FA + GOx at a low-concentration of $0.01 \mu \mathrm{g} \mathrm{mL}^{-1}$ with $808 \mathrm{~nm}$ NIR exhibited a significant cell inactivation effect; the ratio of cell apoptosis was $33.71 \%$, when the GOx concentration was $0.02 \mu \mathrm{g} \mathrm{mL} \mathrm{m}^{-1}$, and the apoptotic ratio could reach $57.5 \%$. Compared with FGO-PEG-FA + GOx, the cytotoxicity of FGO-PEG-FA + GOx + NIR was significantly higher, indicating that PTT could not only effectively induce intracellular hyperthermia, but also promote the decomposition of $\mathrm{H}_{2} \mathrm{O}_{2}$ to produce toxic ${ }^{\circ} \mathrm{OH}$, which finally significantly enhanced the anti-cancer effect. ${ }^{51}$ The above results indicated that the proposed photothermal and starvation treatment strategy can effectively induce the apoptosis of HeLa cells, which was exactly consistent with the MTT cell assay and anti-migration results. Based on the above facts, this highly effective tumor cell therapy method demonstrated satisfactory results and held great promise for future applications.

\section{Conclusions}

In summary, we proposed a new approach based on FGO to achieve synergistic therapy through mild PTT and targeted drug delivery. In this project, we adopted PEG as a medium to connect targeting molecules FA on nanoscale FGO sheets, loaded with GOx to achieve starvation therapy, and used the photothermal properties of FGO for PTT. MTT analysis and apoptosis study demonstrated that GOx effectively released and promoted the formation of ${ }^{\bullet} \mathrm{OH}$ with the aid of PTT. Therefore, a low concentration of GOx could readily realize significant inhibition of tumor cell growth, achieve favorable antimigration effects, and substantially enhance the efficiency and safety of the treatment. This study provided a new strategy for the application of FGO as a new nanocarrier with high values in nano-biomedicine, which developed a broader idea for more efficient synergistic PTT and starvation treatment and thus provided a more effective therapeutic modality for cancer treatment.

\section{Conflicts of interest}

There are no conflicts to declare.

\section{Acknowledgements}

P. W. Gong and Y. Huang contributed equally to this work. The project was sponsored by the National Natural Science Foundation of China (51905304), Natural Science Foundation of Shandong Province (ZR2018QB002) and Young Talents Invitation Program of Shandong Provincial Colleges and Universities.

\section{References}

1 X. Suo, J. Zhang, Y. Zhang, X.-J. Liang, J. Zhang and D. Liu, A nano-based thermotherapy for cancer stem cell-targeted therapy, J. Mater. Chem. B, 2020, 8(18), 3985-4001.

2 H. Wang, Z. Wang, Y. Tu, Y. Li, T. Xu, M. Yang, P. Wang and Y. Gu, Homotypic targeting upconversion nano-reactor for cascade cancer starvation and deep-tissue phototherapy, Biomaterials, 2020, 235, 119765.

3 W.-Q. Huang, F. Wang, A.-Z. Shen, L. Zhang, X. Nie, Z. Zhang, G. Chen, L. Xia, L.-H. Wang, S.-G. Ding, Q.-Y. Meng, W.-J. Zhang, C.-Y. Hong and Y.-Z. You, Single nanosheet can sustainably generate oxygen and inhibit respiration simultaneously in cancer cells, Mater. Horiz., 2021, 8, 645.

4 C. Wei, Y. Liu, X. Zhu, X. Chen, Y. Zhou, G. Yuan, Y. Gong and J. Liu, Iridium/ruthenium nanozyme reactors with cascade catalytic ability for synergistic oxidation therapy and starvation therapy in the treatment of breast cancer, Biomaterials, 2020, 238, 119848.

5 R. Lu, L. Zhou, Q. Liu, S. Wang, C. Yang, L. Hai, L. Guo and Y. Wu, Skillfully collaborating chemosynthesis with GOxenabled tumor survival microenvironment deteriorating strategy for amplified chemotherapy and enhanced tumor ablation, Biomater. Sci., 2021, 9, 1855-1871. 
6 J. Peng, P. Gong, S. Song, K. Zhao, X. Zheng, J. Liu and Z. Liu, Biomineralized synthesis of a smart O2-regenerating nanoreactor for highly efficient starvation/gas therapy, Mater. Sci. Eng., C, 2021, 126, 112132.

7 J. Ming, T. Zhu, W. Yang, Y. Shi, D. Huang, J. Li, S. Xiang, J. Wang, X. Chen and N. Zheng, Pd@Pt-GOx/HA as a novel enzymatic cascade nanoreactor for high-efficiency starvingenhanced chemodynamic cancer therapy, ACS Appl. Mater. Interfaces, 2020, 12(46), 51249-51262.

8 H. Wang, L. Cheng, S. Ma, L. Ding, W. Zhang, Z. Xu, D. Li and L. Gao, Self-assembled multiple-enzyme composites for enhanced synergistic cancer starving-catalytic therapy, ACS Appl. Mater. Interfaces, 2020, 12(18), 20191-20201.

9 Z. Tu, I. S. Donskyi, H. Qiao, Z. Zhu, W. E. S. Unger, C. P. R. Hackenberger, W. Chen, M. Adeli and R. Haag, Graphene oxide-cyclic R10 peptide nuclear translocation nanoplatforms for the surmounting of multiple-drug resistance, Adv. Funct. Mater., 2020, 30(35), 2000933.

10 J. Zhang, L. Liang, Z. Li, Y. Shen, X. Guan, J. Yue, L. Cong, W. Xu, W. Shi, C. Liang and S. Xu, Multi-functionalized nano-conjugate for combating multidrug resistant breast cancer via starvation-assisted chemotherapy, Mater. Sci. Eng., C, 2020, 116, 111127.

11 H. Yu, Z. Yang, F. Li, L. Xu and Y. Sun, Cell-mediated targeting drugs delivery systems, Drug Delivery, 2020, 27(1), 1425-1437.

12 C. Fang, Z. Deng, G. Cao, Q. Chu, Y. Wu, X. Li, X. Peng and G. Han, Co-Ferrocene MOF/glucose oxidase as cascade nanozyme for effective tumor therapy, Adv. Funct. Mater., 2020, 30(16), 1910085.

13 A. Zhang, Q. Zhang, G. Alfranca, S. Pan, Z. Huang, J. Cheng, Q. Ma, J. Song, Y. Pan, J. Ni, L. Ma and D. Cui, GSH-triggered sequential catalysis for tumor imaging and eradication based on star-like Au/Pt enzyme carrier system, Nano Res., 2020, 13(1), 160-172.

14 C. Yang, M. R. Younis, J. Zhang, J. Qu, J. Lin and P. Huang, Programmable NIR-II photothermal-enhanced starvationprimed chemodynamic therapy using glucose oxidasefunctionalized ancient pigment nanosheets, Small, 2020, 16(25), 2001518.

15 G. Gao, Y.-W. Jiang, Y. Guo, H.-R. Jia, X. Cheng, Y. Deng, X.-W. Yu, Y.-X. Zhu, H.-Y. Guo, W. Sun, X. Liu, J. Zhao, S. Yang, Z.-W. Yu, F. M. S. Raya, G. Liang and F.-G. Wu, Enzyme-mediated tumor starvation and phototherapy enhance mild-temperature photothermal therapy, $A d v$. Funct. Mater., 2020, 30(16), 1909391.

16 P. Wang, X. Wang, Q. Tang, H. Chen, Q. Zhang, H. Jiang and Z. Wang, Functionalized graphene oxide against U251 glioma cells and its molecular mechanism, Mater. Sci. Eng., C, 2020, 116, 111187.

17 Y. J. Yun, S.-J. Park, J. Seo, Y.-H. Song, D. H. Ha, H.-M. Chung, Y. Jun and S.-H. Moon, Cellular organization of three germ layer cells on different types of noncovalent functionalized graphene substrates, Mater. Sci. Eng., C, 2019, 103, 109729.

18 J. Song, G. Fei, X. Liu, S. Duan, B. Yang, X. Chen, D. J. Singh, Y. Liu, L. Yang, J. Guo and P. Zhang, Pressure-driven significant phonon mode softening and robust superconductivity in layered germanium phosphide, J. Mater. Chem. A, 2020, 8(38), 20054-20061.

19 X. Sun, C. Huang, L. Wang, L. Liang, Y. Cheng, W. Fei and Y. Li, Recent progress in graphene/polymer nanocomposites, Adv. Mater., 2020, 2001105.

20 S. D. Costa, J. Ek Weis, O. Frank, Z. Bastl and M. Kalbac, Thermal treatment of fluorinated graphene: An in situ Raman spectroscopy study, Carbon, 2015, 84, 347-354.

21 X. Chen, S. Duan, W. Yi, D. J. Singh, J. Guo and X. Liu, Enhanced thermoelectric performance in black phosphorus nanotubes by band modulation through tailoring nanotube chirality, Small, 2020, 16(28), 2001820.

22 Y. Liu, L. Xu, L. Zhang, Z. Dong, S. Wang and L. Luo, Direct visualization of atomic-scale graphene growth on $\mathrm{Cu}$ through environmental transmission electron microscopy, ACS Appl. Mater. Interfaces, 2020, 12(46), 52201-52207.

23 Z. Liu, J. He, T. Zhu, C. Hu, R. Bo, A. Wusiman, Y. Hu and D. Wang, Lentinan-functionalized graphene oxide is an effective antigen delivery system that modulates innate immunity and improves adaptive immunity, ACS Appl. Mater. Interfaces, 2020, 12(35), 39014-39023.

24 S. Kumar and S. H. Parekh, Molecular control of interfacial fibronectin structure on graphene oxide steers cell fate, ACS Appl. Mater. Interfaces, 2021, 13(2), 2346-2359.

25 W. Cao, L. He, W. Cao, X. Huang, K. Jia and J. Dai, Recent progress of graphene oxide as a potential vaccine carrier and adjuvant, Acta Biomater., 2020, 112, 14-28.

26 H. Wang, K. Kurata, T. Fukunaga, H. Takamatsu, X. Zhang, T. Ikuta, K. Takahashi, T. Nishiyama, H. Ago and Y. Takata, A simple method for fabricating free-standing large area fluorinated single-layer graphene with size-tunable nanopores, Carbon, 2016, 99, 564-570.

27 X. Huang, J. Chen, W. Wu, W. Yang, B. Zhong, X. Qing and Z. Shao, Delivery of MutT homolog 1 inhibitor by functionalized graphene oxide nanoparticles for enhanced chemophotodynamic therapy triggers cell death in osteosarcoma, Acta Biomater., 2020, 109, 229-243.

28 V. Mazánek, L. Pavlikova, P. Marvan, J. Plutnar, M. Pumera and Z. Sofer, Fluorine saturation on thermally reduced graphene, Appl. Mater. Today, 2019, 15, 343-349.

29 J. L. Suter, R. C. Sinclair and P. V. Coveney, Principles governing control of aggregation and dispersion of graphene and graphene oxide in polymer melts, Adv. Mater., 2020, 32(36), 2003213.

30 W. Wu, J. Liu, Z. Li, X. Zhao, G. Liu, S. Liu, S. Ma, W. Li and W. Liu, Surface-functionalized nanoMOFs in oil for friction and wear reduction and antioxidation, Chem. Eng. J., 2021, 410, 128306.

31 L. Xu, Y. Zheng, Z. Yan, W. Zhang, J. Shi, F. Zhou, X. Zhang, J. Wang, J. Zhang and B. Liu, Preparation, tribological properties and biocompatibility of fluorinated graphene/ ultrahigh molecular weight polyethylene composite materials, Appl. Surf. Sci., 2016, 370, 201-208.

32 Y. Huang, Z. Xue and S. Zeng, Hollow mesoporous Bi@PEGFA nanoshell as a novel dual-stimuli-responsive nanocarrier 
for synergistic chemo-photothermal cancer therapy, ACS Appl. Mater. Interfaces, 2020, 12(28), 31172-31181.

33 B. Farran, R. C. Montenegro, P. Kasa, E. Pavitra, Y. S. Huh, Y.-K. Han, M. A. Kamal, G. P. Nagaraju and G. S. Rama, Raju, Folate-conjugated nanovehicles: Strategies for cancer therapy, Mater. Sci. Eng., C, 2020, 107, 110341.

34 S. Duan, Y. Cui, X. Chen, W. Yi, Y. Liu and X. Liu, Ultrahigh thermoelectric performance realized in black phosphorus system by favorable band engineering through group Va doping, Adv. Funct. Mater., 2019, 29(38), 1904346.

35 D. Wang, J. Peng, Y. Huang, L. Sun, M. Liu, H. Li, M. Chao, P. Gong, Z. Liu and J. You, Rational construction of fluorescence turn-off fluorinated carbon fiber/Ag composites and their anticancer and antibacterial activities, ACS Appl. Bio Mater., 2021, 4(2), 1749-1759.

36 L. Mochalov, A. Logunov and V. Vorotyntsev, Preparation of gallium of the special purity for semiconductors and optoelectronics, Sep. Purif. Technol., 2021, 258, 118001.

37 Z. Tu, K. Achazi, A. Schulz, R. Mülhaupt, S. Thierbach, E. Rühl, M. Adeli and R. Haag, Combination of surface charge and size controls the cellular uptake of functionalized graphene sheets, Adv. Funct. Mater., 2017, 27(33), 1701837.

38 P. Gong, L. Zhang, X.-A. Yuan, X. Liu, X. Diao, Q. Zhao, Z. Tian, J. Sun, Z. Liu and J. You, Multifunctional fluorescent PEGylated fluorinated graphene for targeted drug delivery: An experiment and DFT study, Dyes Pigm., 2019, 162, 573-582.

39 Y. Xie, W. Li, H. Huang, D. Dong, X. Zhang, L. Zhang, Y. Chen, X. Sheng and X. Lu, Bio-based Radish@PDA/PEG sandwich composite with high efficiency solar thermal energy storage, ACS Sustainable Chem. Eng., 2020, 8(22), 8448-8457.

40 B. Zhang, R. Hu, Y. Wang, C. Yang, X. Liu and K.-T. Yong, Revisiting the principles of preparing aqueous quantum dots for biological applications: The effects of surface ligands on the physicochemical properties of quantum dots, RSC Adv., 2014, 4(27), 13805-13816.

41 A. H. Loo, Z. Sofer, D. Bouša, P. Ulbrich, A. Bonanni and M. Pumera, Carboxylic carbon quantum dots as a fluorescent sensing platform for DNA detection, ACS Appl. Mater. Interfaces, 2016, 8(3), 1951-1957.

42 S. Zheng, X. Li, Y. Zhang, Q. Xie, Y.-S. Wong, W. Zheng and T. Chen, PEG-nanolized ultrasmall selenium nanoparticles overcome drug resistance in hepatocellular carcinoma HepG2 cells through induction of mitochondria dysfunction, Int. J. Nanomed., 2012, 7, 3939-3949.

43 Y. Esmaeili, E. Bidram, A. Zarrabi, A. Amini and C. Cheng, Graphene oxide and its derivatives as promising In-vitro bio-imaging platforms, Sci. Rep., 2020, 10(1), 18052.

44 Y. H. Kim, J. S. Park, Y.-R. Choi, S. Y. Park, S. Y. Lee, W. Sohn, Y.-S. Shim, J.-H. Lee, C. R. Park, Y. S. Choi, B. H. Hong, J. H. Lee, W. H. Lee, D. Lee and H. W. Jang, Chemically fluorinated graphene oxide for room temperature ammonia detection at ppb levels, J. Mater. Chem. A, 2017, 5(36), 19116-19125.

45 W. Feng, P. Long, Y. Feng and Y. Li, Two-dimensional fluorinated graphene: Synthesis, structures, properties and applications, Adv. Sci., 2016, 3(7), 1500413.
46 F. Yan, W. Duan, Y. Li, H. Wu, Y. Zhou, M. Pan, H. Liu, $\mathrm{X}$. Liu and $\mathrm{H}$. Zheng, NIR-laser-controlled drug release from DOX/IR-780-loaded temperature-sensitive-liposomes for chemo-photothermal synergistic tumor therapy, Theranostics, 2016, 6(13), 2337-2351.

47 Z. Lu, J. Gao, C. Fang, Y. Zhou, X. Li and G. Han, Porous Pt nanospheres incorporated with GOx to enable synergistic oxygen-inductive starvation/electrodynamic tumor therapy, Adv. Sci., 2020, 7(17), 2001223.

48 S. Idris, N. H. Azeman, N. A. Noor Azmy, C. T. Ratnam, M. A. Mahdi and A. A. A. Bakar, Gamma irradiated Py/PVA for GOx immobilization on tapered optical fiber for glucose biosensing, Sens. Actuators, B, 2018, 273, 1404-1412.

49 B. Yu, X. Wang, W. Y. Xing, H. Y. Yang, L. Song and Y. Hu, UV-curable functionalized graphene oxide/polyurethane acrylate nanocomposite coatings with enhanced thermal stability and mechanical properties, Ind. Eng. Chem. Res., 2012, 51(45), 14629-14636.

50 S. O. Aisida, A. Batool, F. M. Khan, L. Rahman, A. Mahmood, I. Ahmad, T.-k. Zhao, M. Maaza and F. I. Ezema, Calcination induced PEG-Ni-ZnO nanorod composite and its biomedical applications, Mater. Chem. Phys., 2020, 255, 123603.

51 Z. Deng, Y. He, M. R. Younis, S. Lei, C. Jiang, Y. Yuan, P. Huang and J. Lin, Light-triggered plasmonic vesicles with enhanced catalytic activity of glucose oxidase for programmable photothermal/starvation therapy, Sci. China Mater., 2021, 64(5), 1291-1301.

52 M. Zhai, P. Gong, H. Li, J. Peng, W. Xu, S. Song, X. Liu, J. Liu, J. Liu and Z. Liu, Metastable interface biomimetic synthesis of a smart nanosystem for enhanced starvation/gas therapy, J. Colloid Interface Sci., 2021, 599, 149-157.

53 H. Bao, Y. Pan, Y. Ping, N. G. Sahoo, T. Wu, L. Li, J. Li and L. H. Gan, Chitosan-functionalized graphene oxide as a nanocarrier for drug and gene delivery, Small, 2011, 7(11), 1569-1578.

54 P. Gong, Q. Zhao, D. Dai, S. Zhang, Z. Tian, L. Sun, J. Ren and Z. Liu, Functionalized ultrasmall fluorinated graphene with high NIR absorbance for controlled delivery of mixed anticancer drugs, Chem. - Eur. J., 2017, 23(69), 17531-17541.

55 Y. Wang, H. Song, G. Wang, X. Yang, J. Wang and H. Wei, 131I-labeled PEG and folic acid co-functionalized graphene quantum dots for tumor-targeted imaging, J. Radioanal. Nucl. Chem., 2019, 319, 1119-1125.

56 K. Fan, X. Liu, Y. Liu, Y. Li, Y. Chen, Y. Meng, X. Liu, W. Feng and L. Luo, Covalent functionalization of fluorinated graphene through activation of dormant radicals for water-based lubricants, Carbon, 2020, 167, 826-834.

57 P. Gong, L. Zhang, J. Peng, S. Li, J. Chen, X. Liu, H. Peng, Z. Liu and J. You, Smart "on-off-on" fluorescent switches for drug visual loading and responsive delivery, Dyes Pigm., 2020, 173, 107893.

58 Y. Cao, J. Feng and P. Wu, Alkyl-functionalized graphene nanosheets with improved lipophilicity, Carbon, 2010, 48(5), 1683-1685. 
59 J. G. Riess and M. P. Krafft, Fluorinated materials for in vivo oxygen transport (blood substitutes), diagnosis and drug delivery, Biomaterials, 1998, 19(16), 1529-1539.

60 Y. Jiang, S. Deng, S. Hong, S. Tiwari, H. Chen, K.-i. Nomura, R. K. Kalia, A. Nakano, P. Vashishta, M. R. Zachariah and $\mathrm{X}$. Zheng, Synergistically chemical and thermal coupling between graphene oxide and graphene fluoride for enhancing aluminum combustion, ACS Appl. Mater. Interfaces, 2020, 12(6), 7451-7458.
61 J. Peng, P. Gong, S. Li, F. Kong, X. Ge, B. Wang, L. Guo, Z. Liu and J. You, A smart bioresponsive nanosystem with dual-modal imaging for drug visual loading and targeted delivery, Chem. Eng. J., 2020, 391, 123619.

62 P. Gong, L. Sun, F. Wang, X. Liu, Z. Yan, M. Wang, L. Zhang, Z. Tian, Z. Liu and J. You, Highly fluorescent N-doped carbon dots with two-photon emission for ultrasensitive detection of tumor marker and visual monitor anticancer drug loading and delivery, Chem. Eng. J., 2019, 356, 994-1002. 